\title{
LA REINVENCIÓN FREIRIANA EN la universidad: Paulo Freire, EL MOVIMIENTO ZAPATISTA, EL PSICOANÁLISIS SOCIOPOLÍTICO Y LA PEDAGOGÍA ERÓTICA ${ }^{1}$
}

\author{
A reinvenção freiriana na universidade: Paulo Freire, \\ O MOVIMENTO ZAPATISTA, A PSICOANÁLISE SOCIOPOLÍTICA E A \\ PEDAGOGIA ERÓTICA
}

\author{
The ReINVENTION of PaUlo Freire IN THE UNIVERSITY: \\ PaUlo Freire, THE ZAPATISTA MOVEMENT, THE \\ SOCIOPOLITICAL PSYCHOANALYSIS AND THE EROTIC PEDAGOGY
}

\section{Miguel Escobar Guerrero \\ Profesor en la FFyL, Unam. http://www.lrealidad.filos.unam.mx/ maeg@unam.mx}

\begin{abstract}
Resumen: Cuando me despedí de Paulo Freire en Ginebra (Suiza) en 1978, un sueño llegó conmigo a México: reinventar a Freire y no solamente repetirlo. Comencé ese mismo año a trabajar en la Facultad de Filosofía y Letras, FFyL, Unam. En 1994 me encontré frente al grito de lucha de las comunidades zapatistas "YYa Basta!" que le daba vida revolucionaria al pensamiento freiriano. Ese " $\mathrm{ia}$ Basta!" me desafió a ir a la praxis desde la práctica y no sólo desde la teoría, lo que permitió definir mejor el proyecto de investigación - La lectura de la realidad en el aula. Pensar la práctica para transformarla. El escrito que aquí se presenta es la síntesis de un caminar, entre profesor y estudiantes, pensando la práctica para transformarla. Proceso que gestó una metodología, MRCyT, la cual ha permitido que quienes participan en el proceso educativo emerjan como sujetos capaces de "pronunciar" su mundo.
\end{abstract}

Palabras clave: Paulo Freire. La perversión en la globalización. El movimiento zapatista. El psicoanálisis sociopolítico. La pedagogía erótica.

Resumo: Quando me despedi de Paulo Freire em Genebra (Suíça) em 1978, levei comigo para o México um sonho: reinventar Paulo Freire; náo apenas repeti-lo. Nesse mesmo ano, comecei a trabalhar na Faculdade de Filosofia e Letras (FFyL, Unam). Em I994, encontrei-me diante do grito de luta das comunidades zapatistas, "Já Basta!", que dava vida revolucionária ao pensamento freiriano. O "Já Basta!" desafiou-me a ir para a 
práxis, a partir da prática e, não apenas da teoria, o que permitiu uma melhor definição do projeto de pesquisa: "A leitura da realidade na aula: Pensar a prática para transformála”. O texto que aqui se apresenta é a síntese de um caminhar, de professor e estudantes, pensando a prática para transformá-la. Este processo gerou uma metodologia, MRCyT, que tem permitido a quem participa do processo educacional emergir como sujeito capaz de pronunciar seu próprio mundo.

Palavras-chave: Paulo Freire. A perversão na gobalização. O movimiento zapatista A psicoanálise sociopolítica. A pedagogia erótica.

\begin{abstract}
Aвstract: After I bid farewell to Paulo Freire in Geneva (Switzerland) in 1978, I brought a dream with me to Mexico: to reinvent Freire, not just to repeat him. In that same year, I began working at the Faculty of Philosophy and Literature (FFyL) of the National Autonomous University of Mexico (Unam). In 1994, I found myself facing the clamor of the zapatista communities: "It is enough!», which instilled Freire's thoughts with revolutionary life. That «It is enough!» challenged me to define my work in terms of practice and not just theory, which helped define my research project Reading Reality in the Classroom. Thinking Practice in order to Transform It. This writing is the synthesis of a dialogue between a professor and students, who are rethinking practice in order to transform it. This process led to the development of the MERCyT methodology, which has allowed those participating in the educational process to emerge as subjects capable of enunciating their own world.
\end{abstract}

Key words: Paulo Freire. Perversion in globalization. Zapatista movement. Sociopolitical psychoanalysis. Erotic pedagogy.

Hermano Juan Chávez, hoy te decimos que las semillas que has sembrando a lo largo de todo el país están creciendo y nos ayudan a hacer frente a las inmensas dificultades que viven todos los territorios de nuestros pueblos.

\title{
¿ESCUCHARON?3
}

Es el sonido de su mundo derrumbándose.

Es el del nuestro resurgiendo.

El día que fue el día, era noche.

Y noche será el día que será el día. 


\section{¡DEMOCRACIA! \\ ¡LIBERTAD! \\ ¡JUSTICIA!}

Podemos concluir que la vocación de la utopía no es la de ir hacia la realidad y buscar su realización - sino al contrario como lo intenta repetirlo aquí, levantarse contra su rival más duro, su adversario más insolente o real y de afirmarse frente a su más rudo rival [...] la utopía hacia la realidad pero exactamente lo contrario: la utopía contra la realidad - utopía versus realidad, la utopía contra la realidad. ${ }^{4}$

¿Por qué existen seres humanos que no pueden dejar de luchar socialmente, mientras otros bajan los brazos y aceptan el statu quo, la injusticia social, el hambre y la miseria social?s

Cuando me despedí de Paulo Freire ${ }^{6}$ en Ginebra (Suiza) en 1978, un sueño llegó conmigo a México: reinventar a Freire y no solamente repetirlo. Comencé ese mismo año a trabajar en la Facultad de Filosofía y Letras, FFyL, de la Universidad Nacional Autónoma de México, Unam. En 1994 me encontré frente al grito de lucha y de rebelión de las comunidades zapatistas, ; $Y a$ Basta! que le daba vida revolucionaria al pensamiento freiriano. Ese ;Ya Basta! me desafió a ir a la praxis desde la práctica y no sólo desde la teoría, lo que permitió definir mejor el proyecto de investigación - La lectura de la realidad en el aula. Pensar la práctica para transformarla - que orienta mi labor educativa en el Colegio de Pedagogía y el Posgrado en Pedagogía de la FFyL. Así constaté que la mejor forma de reinventar a Freire, como de aprender de la propuesta zapatista era de llevarlas a la práctica docente. $Y$, a partir de la práctica, conjuntamente con quienes participan en ella, fuimos construyendo un conocimiento donde el concepto - las categorías y la teoría que los sustenta -, se utilice como un puente, como una ventana para entender mejor la praxis desde la práctica y no aquella que se queda en la teoría. Así mejor iluminar nuestra acción sin caer ni en el verbalismo ni en el activismo como decía Freire. Una praxis que permita la construcción, como palabra-acción, de un mundo que se reinvente de abajo hacia arriba, un mundo que pueda contener diferentes 
mundos como dicen y hacen actualmente las comunidades zapatistas en lucha, resistencia y organización.?

El escrito que aquí se presenta es la síntesis de un caminar, entre profesor y estudiantes, pensando la práctica para transformarla. Proceso que gestó una metodología, La metodología para el rescate de lo cotidiano y la teoría en el aula, MRCyT, la cual ha permitido que quienes participan en el proceso educativo emerjan como sujetos capaces de "pronunciar" su mundo.

Uno de los resultados de este proceso es la escritura de un libro conjunto, entre docente y profesoras adjuntas, Descifrar tu mirada... donde se propone leer de otra forma la realidad educativa, social y emocional, juntando la razón racional y la razón inconsciente con la razón poética. Aquí se cuenta parte de la historia que se entrelaza en el libro, describiendo la importancia de traer las luchas sociales al salón de clases.

Los procesos educativos pueden ser portadores de sueños y utopías contrarios a la imposición del capitalismo salvaje que hoy gobierna el mundo y ha consolidado el poder de Tánatos. Aquí proponemos la "pedagogía erótica" para "pronunciar" el mundo al lado de los Nadies, las y los olvidados de la historia, hoy daños "colaterales" de la globalización neoliberal. Esta propuesta educativa al contrario de ser neutra, es directiva y reivindica el papel de una autoridad colectiva que se construya dentro de una praxis que rescata la práctica y la teoría.

La Pedagogía que proponemos lejos de ser neutra, propone una dirección colectiva, sustentada en el principio de autoridad colectivo que tiene como referente la praxis de mandar obedeciendo" de las comunidades zapatistas, donde el pueblo manda y quien asume la autoridad obedece. Una praxis que rompa las barreras del salón de clases.

Muchas preguntas orientan nuestro caminar, desde compromiso ideológico y político abajo y a la izquierda:

¿Cómo emparejarse para definir consensos, construyendo la "nosotridad"? ¿Cómo recuperar la memoria histórica social e individual? ¿De qué memoria se trata? ¿De dónde venimos, dónde estamos y para dónde vamos? ¿Cómo descifrar el modelo de globalización de la usura, la perversión y la guerra como negocio y manifestación de la crueldad? ¿Cómo combatir el imperio mediático, en especial el de la televisión, como falsa mediadora que tergiversa la realidad para anestesiar a la sociedad? ¿Cómo 
lograr una información veraz y oportuna a través de los medios alternativos, además del Facebook y Twitter? ¿Cuál es la nueva relación que nace y se construye entre el liderato individual y colectivo? ¿Cuáles son los límites de los movimientos juveniles? ¿Cómo leer esa realidad? ¿Cómo prepararse y desactivar la confrontación - "filicida", "parricida" y "fratricida" - que continuamente diseñan e implementan quienes son poder económico, financiero, religioso, militar y político para no perder sus privilegios? ${ }^{\text {1o }}$ ¿Cómo rescatar el pensamiento como praxis colectiva? y, ¿Cómo entender la lucha de clases?

Los principales resultados de este proceso educativo los podemos resumir en seis puntos principales: Descifrar tu mirada; Medios de comunicación de paga y perversión; Diálogo y directividad; Paulo Freire y el EZLN; Eros y Tánatos: ¿La lucha social es posible en el aula? ; Lectura de la realidad y metodología.

\section{Descifrar tu mirada}

El libro Descifrar tu mirada es una flor de la palabra, de la palabra $\leftrightarrow$ acción, de la palabra que es al mismo tiempo concepto y acción. El libro es una síntesis del proyecto de investigación práctico y teórico donde la finalidad es desarrollar una praxis colectiva. Pero, teniendo presente que para mejor construir la práctica es necesario aprender a preguntar, "emparejándonos" con el otro(a), para "pronunciar" nuestro mundo con los Nadies: los arrinconados en el basurero de la historia: las y los desarrapados del mundo y condenados de la tierra. La palabra de este libro - relato, poesía, novela, denuncia y canciones - es la voz del no olvido, en una epistemología que invita a diseñar una educación anclada en su contexto sociopolítico donde, entre otras cosas, la memoria histórica permita rescatar y dar sentido a un principio de justicia social roto con la imposición del modelo de globalización neoliberal. ${ }^{\text {II }}$

El acto de justicia también es producto de una renuncia pulsional a favor del otro y nace cuando se espera que sea correspondida de la misma manera. Es una transacción que tiene la característica de mantener en igualdad de circunstancias a dos 
o más seres humanos que tienen un mismo derecho y una misma obligación [...] Es una especie de arreglo que versaría así: no te elimino, siempre y cuando tú no intentes eliminarme a mí. Por esta razón, bien podríamos decir que la justicia no es sólo un acto de moralidad que nos dignifica, sino que es, además y ante todo, un acto que nace de la necesidad biológica de supervivencia. De ahí que cuando se comente una injusticia, se siente como un atentado contra la propia vida.

Descifrar tu mirada es el resultado entonces de nuestra propuesta metodológica, MRCyT, la que dio nacimiento a la "pedagogía erótica" como construcción del sentido de la vida, de la fuerza de Eros capaz de detener el Tánatos que se hizo poder. Esta Pedagogía reivindica un proceso educativo donde el profesor y la profesora, al enseñar $\leftrightarrow$ aprendiendo, hacen posible que las y los estudiantes emerjan como sujetos comprometidos socialmente con ellos y ellas mismas. Su propuesta también reivindica el principio de autoridad: la autoridad que aplasta la libertad es autoritaria pero la libertad que aplasta la autoridad es libertinaje. ${ }^{\mathrm{I2}}$

En la "pedagogía erótica" la construcción de la autoridad no está dada, se valida colectivamente en el respeto mutuo entre docente y estudiantes, como hoy lo señalan y hacen suyo la mayor parte de los movimientos sociales que salen en defensa de la vida, de una democracia real, y contra la mentira que se hizo poder y se apoya en los medios de comunicación, en especial la televisión, para tergiversar la realidad. Es necesario, por ello, la observación y el estudio de la autoridad $\rightarrow$ autoritaria: sus consecuencias, cuando al desbordar sus límites abre las puertas a esas partes muy primitivas del ser humano: expresión de la conducta psicopática, el filicidio y el fratricidio que en este texto trabajamos. ${ }^{13}$

El psicoanálisis permite definir la conducta psicopática en las manifestaciones de una conducta agresiva que tiene como fin el causar un mal al otro/otra. La persona que la manifiesta no tiene la capacidad de soportar la frustración que le produce él no poderse apropiar de los objetos que desea y decide tomarlos por la fuerza. Esa persona produce un daño individual y social con su actitud. 
Y, la conducta filicida es también de gran importancia para la observación y el estudio del ser humano y no podemos seguir negando esta conducta en sus manifestaciones transparentes u ocultas. ${ }^{\mathrm{I}}$

Sus formas atenuadas más evidentes están constituidas por la circuncisión, el abandono temprano y/o reiterado, el castigo, la prohibición instintiva, la amenaza, la castración, las penalidades y mortificaciones, la crueldad, los ataques físicos o verbales, las negaciones despóticas, la insensibilidad ante el sufrimiento, el juicio denigratorio y todas las formas de actitud parental ocasional o persistente que se impriman con heridas en el Yo con consecuencias inmediatas o remotas...

\section{Medios de comunicación de paga y perversión}

Pocos días antes del inicio de la huelga de la Unam, I999-2000, algunos y algunas estudiantes me invitaron a realizar un "Taller autogestivo Paulo Freire" para "Leer la huelga". El espacio del taller nos permitió "leer" el movimiento estudiantil, analizándolo a través de los "medios de desinformación y control del pensamiento", con la finalidad de observar y de estudiar el acontecer cotidiano, tratando de identificar el tipo de conducta seguida por las autoridades - de la universidad y del gobierno - que se manifestaba con la firme intención de desprestigiar y de victimar a los estudiantes. Este estudio nos llevó a percatarnos de que estábamos inmersos y atrapados dentro de una psicopatía del poder y de que el movimiento estudiantil era presa fácil, de un comportamiento psicopático. ${ }^{\text {Is }}$ Fernando Martínez señaló que desde el año I968 se pudo observar al mismo tiempo el deseo de los(as) jóvenes de participar la dirección política del país y la respuesta filicida y fratricida del poder político. En ese año en México la represión filicida produjo miles de muertes que continuan en la actualidad.

El salón de clases es un termómetro social y, por ello, nuestra propuesta educativa va más allá de sus muros - reales o virtuales - entendiendo que el conocimiento que se transmite, y crea, también vehicula deseos, sueños, utopías y luchas. Deseos de dar sentido a la vida como expresión de esa energía que conforma al ser humano, en una relación dialéctica, entre 
la ética erótica de Eros y su contrario, la ética erótica de Tánatos que hoy se hizo poder en la sociedad. ${ }^{16}$

Este proceso queda perfectamente instaurado y consolidado gracias a la estimulación de las partes xenofóbicas de todos aquellos que, queriendo lo mejor para sus hijos, participan en la creación de una "elite educada" que se aleja de la gran masa, del "populacho", confirmando con ello en su interior, la superioridad que han obtenido sobre los demás, quienes no tienen más destino que el morirse de rabia por no poder alcanzar ese preciado nivel de vida. Ese deseo de eliminar al otro es, por cierto, bastante conocido por el ser humano pues constituyó su primera reacción en contra del hermano cuando se sintió amenazado con que le robaran el cariño y la atención de los padres y del cual sólo fue factible ceder cuando los padres pudieron demostrarle que existía suficiente cariño para el que recién llega y para el que ya estaba. Sin embargo, ese impulso de eliminar al otro para desplazarlo, nunca cede en su totalidad y basta con que alguien lo sepa estimular para que otra vez aparezca en infinidad de formas.

La historia de Descifrar tu mirada se desarrolla a partir de una relación amorosa entre Lisa y Marcos, protagonistas del libro, quienes entrelazan las luchas sociales fuera y dentro del salón de clases. Ella, una luchadora social que es violada en una agresión - como tantas que se viven y mueren cotidianamente - contra el pueblo de San Salvador Atenco, en México. Él, un profesor universitario, también comprometido desde el aula con la construcción de una sociedad con justicia, libertad y democracia, y dispuesto a conocer la verdadera causa por la que Lisa decidió abandonarlo después de haber estado presente en la defensa de Atenco. ${ }^{17}$

El pueblo de San Salvador Atenco donde el gobierno había tendido una trampa a sus habitantes para vengarse, entre otras cosas, por no haber permitido la construcción de un aeropuerto para la ciudad de México. Ese pueblo, como tantos otros en nuestro mundo actual, por ejemplo en Francia, Notre dame des Landes, donde actualmente sus pobladores están en resistencia y organización para impedir la construcción de un aeropuer- 
to. De la misma forma que en México, se pretende la devastación de sus tierras bajo la lógica capitalista. El poder político de la gran capital continua ignorando la cultura, la historia, el modo de vida y la razón de sus habitantes. Es la lógica del mercado, de la concepción del hombre-mercancíaconsumo que a cualquier precio busca borrar del mapa sus tierras, o sea, su madre tierra, su historia, su cultura, su vida y sentido de ella.

En esa agresión contra el pueblo de Atenco, también estaba la intención de detener la marcha de la "otra Campaña" -que inició en el 2006 para invitar a la sociedad tanto a crear autonomías basadas en "mandar obedeciendo" como para mostrar a la sociedad la falsedad de los partidos políticos, su desconexión con la realidad cotidiana de hambre y miseria de los Nadies. Un llamado a la organización desde abajo y a la izquierda. El EZLN había decidido que el "delegado Zero", o sea, el Subcomandante Marcos, encabezara la marcha para compartir en todo el país experiencias de resistencia, de dolor, de lucha y para sembrar la Digna Rabia. ${ }^{{ }^{8}} \mathrm{La}$ "otra Campaña”, más allá de la partidocracia, fue de gran importancia para una sociedad que después de acompañar las demandas zapatistas, había guardado silencio cuando el gobierno y los partidos políticos traicionaron los Acuerdos de San Andrés, que eran un primer paso para la firma de la paz con el gobierno. ${ }^{19}$

Para el mal gobierno, también era necesario detener, a cualquier precio, el recorrido del "delegado Zero". Y Atenco fue la trampa perfecta. Como consecuencia de ello, en la historia del libro, Lisa - como ocurrió en la realidad con varias mujeres $-{ }^{20}$ queda atrapada, es violada y presa en una agresión salvaje contra su dignidad y no puede expresar a Marcos la verdad de lo ocurrido. Había caído en un "estrés postraumático", tan presente hoy en nuestras sociedades sembradas por guerras y agresiones constantes, con sus consecuencias sociales, políticas y emocionales. Por alguna razón desconocida que Marcos no lograba descifrar, Lisa es orillada a desconectarse de su realidad de lucha y compromiso social, y perdiendo el sentido de la vida.

Pero, ¿por qué entonces escribir un libro sobre estos temas?

Es difícil responder esta pregunta pero pensamos que es esencial sembrar la semilla de la Digna Rabia, de un saber aprender a leer la práctica en un trabajo que históricamente es asumido por quienes están dispuestas y dispuestos a no callar y dar sentido a su vida colectivamente. La idea, 
por lo tanto, era proponer otra forma de leer la realidad desde el aula. Y, de eso se trata nuestro proyecto de "La lectura de la realidad en el aula. Pensar la práctica para transformarla". En su largo recorrido el primer objeto de estudio fue la participación estudiantil, actualmente es la construcción colectiva de conocimientos. En este trabajo práctico y teórico, las y los estudiantes construyen su subjetividad colectiva donde los escritos colectivos tienen una fuerza muy importante. Ya no es el profesor que construye el conocimiento individualmente, la mayoría de las veces a partir de los trabajos estudiantiles.

\section{Diálogo y directividad}

En nuestra propuesta educativa el sello del acto epistemológico es el diálogo. El educador, la educadora piensan la práctica "con" las y los educandos y no sólo "para" ellos: los dos son sujetos del acto de conocimiento. Pensar la práctica tiene dos momentos dialécticamente unidos: uno, la transmisión de los conocimientos producidos, pertinentes a la problemática que se estudia. El otro, la creación del conocimiento nuevo, pensando conjuntamente la práctica. Aquí es esencial la elaboración de propuestas metodológicas - nunca como modelos sino como caminos epistemológicos, ideológicos y políticos - donde quienes participan en ese proceso aparezcan como sujetos estudiosos de una práctica escolar inserta en un contexto social, financiero, cultural, militar, familiar, religioso, político y marcado principalmente por las relaciones de opresión inherentes al sistema capitalista.

El acto educativo no es neutro, por el contrario es directivo. La construcción de sueños y utopías como los de una sociedad que se reinvente da abajo hacia arriba, donde no exista la explotación de unos sobre otros y donde sea menos difícil amar, hacen parte intrínseca de dicha directividad. Por ello, el acto educativo como acto político emancipador es también una lectura de las luchas sociales, identificando constantemente la ideología dominante, impuesta principalmente por los medios de información de paga, que al tergiversar la realidad, anestesia a los seres humanos para inmovilizarlos, convertirlos en sonámbulos e impedir que salgan en la defensa de la vida. ${ }^{21}$ 
Para entender el funcionamiento de la política de arriba, hay que acudir a su nuevo ateneo: los medios de comunicación de paga. Ojo: noten ustedes que no usé el tradicional "medios masivos de comunicación" porque hay medios alternativos (o libres o como se diga) que son masivos y otros que son de terreno de lucha (como el internet).

Un empuje definitivo en nuestro proyecto fue la consolidación de un equipo de trabajo formado por docentes, estudiantes y profesoras adjuntas en las materias impartidas en la $\mathrm{FFyL}^{22}$ - pero también durante varios seminarios realizados en distintas instituciones donde se ha implementado la MRCyT. ${ }^{23}$ Este empuje se vio reflejado, entre otras muchas cosas, en la elaboración de la página web del proyecto. ${ }^{24}$ La participación colectiva llevó también a la escritura del libro al que nos estamos refiriendo.

En el libro se narran y analizan dos hechos importantes vividos en México: uno, la incapacidad del gobierno mexicano para entender, identificar y gestionar la gripe de influenza A/HINI. El otro, la violencia, muerte y violación de mujeres, como mensaje de escarmiento contra el Pueblo de San Salvador Atenco. ${ }^{25}$ Pero Descifrar tu mirada. De Caledonia a Playa Careyes también marcó el encuentro de la teoría con la literatura, con la poesía y la música, ${ }^{26}$ buscando juntar la razón poética, teórica y emocional para compartir, de forma más creativa, la lectura de la realidad en el aula. Compartir la esperanza en la lucha solidaria.

En el contexto de nuestra propuesta educativa, el libro explora las relaciones amorosas dentro de una sociedad capitalista de mercancía, al servicio de un capitalismo de guerra, especulativo y transnacional, desconectado de la realidad de hambre y miseria, impuesto con violencia y dejando como su fruto el rompimiento del tejido social y la desesperanza. ${ }^{27}$

Lisa y Marcos están inmersos en la realidad real de una autoridad $\rightarrow$ autoritaria, bajo una agresión y crueldad exhibida - y en parte alentada - por la mayoría de los medios de paga. ${ }^{28}$ No es por azar que las y los jóvenes en México, en el contexto de las elecciones de julio de 2012 para elegir presidente de la República, se organizaron - Yo soy I32 - en contra de lo que consideraron la imposición del candidato de Televisa, quien "ganó" la elección plagada de irregularidades. ${ }^{29}$ El canal de Televisa está ligado directamente al Partido Revolucionario Institucional (PRI), que gobernó con represión 
durante 70 años en México. Es una cadena de televisión que, como dijera su dueño, es el soldado de ese partido político. Desde la perspectiva de nuestra investigación de la lectura de la realidad, hemos observado y estudiado los efectos perversos que causan la tergiversación de la realidad y es de gran importancia que las y los jóvenes salgan en defensa de la vida denunciando y organizándose para no seguir permitiendo que la impunidad de quienes tergiversan la realidad para intentar inmovilizar a la sociedad..$^{30}$

En la historia del libro, Lisa pensaba que la lucha social sin el amor no tiene sentido, no funciona y que éste en las relaciones de parejas, también es un acto político. Ella defendía la importancia del diálogo permanente para identificar a favor de qué y de quién camina la utopía y, por lo tanto, en contra de qué y de quién. Pero, después de la agresión en Atenco ella quedó abandonada a su propio destino, a esa "suerte" de la desesperanza que parece imponerse a la sociedad como daño colateral a la "utopía” al revés - distopía - del capitalismo salvaje.

Todos los conocimientos emanados de la praxis de Lisa con los Nadies, de pronto no tuvieron más sentido para ella, se derrumbaron y la arrinconaron en otro sótano, el de la desconexión de la realidad, tal vez esa psicosis manifestada por un poder político que rompió con la realidad social. Sola, como sonámbula, seguía caminando un mundo que ya le era ajeno. Pero, no estaba sola totalmente. Ni su pareja Marcos ni las comunidades con las que trabajaba se olvidaron de ella pero, su respuesta tardó en venir, no fue fácil. No lo es, salir en defensa del hermano(a), de la vida, ante la agresión de una autoridad $\rightarrow$ autoritaria y filicida que intenta impedir y/o destruir las redes de solidaridad, escondiendo su conducta psicopática en el enfrentamiento fratricida: en las luchas sociales enfrentar los buenos hermanos contra los malos y en las guerras mandar a las y los hijos a que se maten. "De ahí la atención permanente en ese sentido que tienen que ejercer los movimientos sociales”. El poder siempre dice que quiere dialogar mientras perversamente diseña, implementa, lanza su agresión simbólica y real.

Finalmente las comunidades con las que trabajaba, logran expresar a Lisa:

Nos duele y sigue llenando de Digna Rabia - comprobar cotidianamente que el gobierno escribe sobre nuestros cuerpos vio- 
lados la palabra ESCARMIENTO. Todos formamos parte del todo y aquello que afecta a uno, afecta a toda la comunidad, porque "Todos somos responsables los unos de los otros". Tenemos un mismo corazón que se explica en una frase en lengua maya que dice: lajan lajan "aytik" (estamos parejos) que significa que "somos iguales y como tales, formamos parte de una gran comunidad de sujetos con corazón" pues es sujeto todo aquel o aquello que tiene corazón. No te rindas [...] No te canses [...] No te sueltes, que el calor de tus manos es la fortaleza de las nuestras. No cierres los ojos, porque son la coyuntura de nuestra lucha por un mundo más humano. Tu mano suave y adusta acaricia una tiza para pronunciar el mundo. Sabemos que nos haces falta porque contigo compartimos nuestro mundo. Eres cómplice del deseo puesto en la lucha por un mundo construido de abajo hacia arriba.

\section{Paulo Freire y el EZLN}

Como ya lo analizamos, la epistemología freiriana es un proceso que busca tanto la transformación de la práctica educativa y social como construir conocimientos ligados a ella. Sin embargo, la aparición del EZLN en 1994, no sólo enriqueció nuestro proceso de lectura de la realidad en el aula sino que nos confrontó a esa realidad mexicana y mundial, de opresión y emancipación, de resistencia y lucha, de esperanza y desesperanza. Se fue gestando la Digna Rabia zapatista que se hace camino convocando a la sociedad a crear autonomías, a no confiar en un poder político que dice querer negociar y dialogar, mientras que en su doble discurso prepara e implementa su agresión, apoyado en el poder de los medios de información de paga que, a su vez, dicen querer informar mientras tergiversan la realidad para confundir e inmovilizar a la sociedad. ${ }^{31}$

El camino de la Digna Rabia propuesto por el EZLN es juntar rabias, luchas y dignidades para organizarse aprendiendo a "mandar obedeciendo" impidiendo lideratos que mandan mandando, sin quedarse en la rabia y rebeldía solamente, o sea, ir a la palabra-acción. En la Sexta Declaración de la Selva Lacandona, La sexta, se precisa su, digamos en tér- 
minos freirianos, directividad: hace una convocatoria a ocupar y ejercer el poder social con una visión ideológica, abajo y a la izquierda, para preparar un levantamiento social pacífico que se construya colectivamente para no caer en mesianismos, en el poder de partidos políticos que quisieran adueñarse de procesos sociales y revolucionarios. Pero, la Sexta también es una convocatoria a nivel nacional y mundial para luchar contra el neoliberalismo y por la humanidad. Convocatoria que se ha ido consolidando y definiendo autónomamente desde las organizaciones anti capitalistas hasta los indignados en Europa y los Ocupa en Estados Unidos y con las revueltas de la mal llamada Primavera Árabe en el Norte de África y los países árabes. Y, para sorpresa y gratitud de muchas y muchos de nosotros, esa primavera que hace camino en tierras mexicanas. ${ }^{32}$

Ahora vamos a explicarles cómo es que vemos nosotros los zapatistas lo que pasa en el mundo. Pues vemos que el capitalismo es el que está más fuerte ahorita. El capitalismo es un sistema social, o sea una forma como en una sociedad están organizadas las cosas y las personas, y quien tiene y quien no tiene, $y$ quien manda y quien obedece. En el capitalismo hay unos que tienen dinero o sea capital y fábricas y tiendas y campos y muchas cosas, y hay otros que no tienen nada sino que sólo tienen su fuerza y su conocimiento para trabajar; y en el capitalismo mandan los que tienen el dinero y las cosas, y obedecen los que nomás tienen su capacidad de trabajo [...] Y también el capitalismo hace su riqueza con despojo, o sea con robo, porque les quita a otros lo que ambiciona, por ejemplo tierras y riquezas naturales. O sea que el capitalismo es un sistema donde los robadores están libres y son admirados y puestos como ejemplo.

Y, además de explotar y despojar, el capitalismo reprime porque encarcela y mata a los que se rebelan contra la injusticia [...] Entonces, como quien dice que resumiendo, el capitalismo de la globalización neoliberal se basa en la explotación, el despojo, el desprecio y la represión a los que no se dejan. $\mathrm{O}$ sea igual que antes, pero ahora globalizado, mundial. 
Una de las aportaciones de la epistemología zapatista es la de aprender a caminar preguntando, teniendo como espejo el tiempo de la dignidad mancillada pero convertida en Digna Rabia de organización y lucha.

Fuimos aprendiendo, por lo tanto, que lo importante es saber leer la práctica para transformarla y que una sola teoría no es suficiente para responder a tantas preguntas y desafíos a los que nos confronta dicha práctica y que, por el contrario, es indispensable la construcción de un pensamiento crítico, donde palabra y acción, la praxis desde la práctica y no solo una praxis desde la teoría camina preguntando colectivamente. Pero, como el salón de clases no es un espacio para el proselitismo político, tampoco neutro, se necesita la claridad en la postura de docentes explicando sus sueños y utopías, su posición política, ideológica, epistemológica y teórica.

\section{Eros y Tánatos: ¿̨a lucha social es posible en el aula?}

Volviendo a la historia entre Lisa y Marcos, para estos dos personajes la utopía se entiende como expresión permanente de su deseo, va más allá de la relación de pareja, es ella la brújula que da dirección y sentido a la existencia. La utopía también tiene su impulso en relaciones de parejas que, en su continuo devenir, conjuntan proyectos de vida, en un enamoramiento que, con cualidades y defectos, son la energía que posibilite la continua reinvención del ser humano, asumiendo que en su devenir no es un ser ni fechado, ni dado, ni determinado.

Lisa estaba más en la acción, en la expresión de sentimientos. Marcos más en la teoría, en la explicación de sentimientos pero, los dos caminando juntos su erotismo y su compromiso social e individual.

Para Lisa y Marcos el Eros es siempre manifestación de vida, de creatividad, de generosidad, de erotismo de Eros y de Tánatos, de ese amor que se expresa de múltiples formas en cada ser humano y en la sociedad. ${ }^{33}$ Ella y él habían comprendido que el erotismo también es expresión de un Tánatos que tiene su acento, entre otras cosas, en las relaciones sociales marcadas por esas partes muy primitivas del ser humano, muy arcaicas y destructivas. Por ello, no aceptaban ese autoritarismo filicida, fratricida y, por lo tanto transgresor, de una justicia social igual para todos. Y, entendían desde su práctica que el ser humano vive entre la norma y la 
transgresión, entre el ángel y la bestia, entre la pulsión de vida y la pulsión de muerte y estaban conscientes de que la parte transgresora de quienes conforman los movimientos sociales hace parte también de esa condición humana de erotismo de Tánatos, pero que es destructora de movimientos sociales emancipadores. ${ }^{34}$ De ahí la necesidad de observarlos y conocerlos para denunciarlos, organizándonos para impedirlos.

En el libro se plantean también otras preguntas fundamentales como: ¿desde dónde y cómo se va construyendo el principio de autoridad?, ¿qué relación tiene la dialéctica filicida, parricida y fratricida con el principio de autoridad?, ¿̧hasta dónde la aceptación de la norma permite una relación dialéctica entre Tánatos y Eros donde el vencedor sea este último?, ¿qué relación debe existir entre los sentimientos y la explicación de ellos?

En el concepto de erotismo, que es una construcción humana en su razón racional y su razón emocional, es el que proponemos en este libro buscando "leer" con otros conceptos el sentimiento de amor y de ternura. $\mathrm{Y}$, al mismo tiempo, la agresión amorosa, la muerte. El erotismo permite conocer al ser humano en su sexualidad como energía de su cuerpo, en su libido y en su deseo, incluyendo la lucha entre vida y muerte, o sea, el deseo de Eros pero también el de Tánatos.

Para Roger Dadoun, ${ }^{35}$ prohibición y transgresión son los dos principios sobre los cuales George Bataille elabora su concepto de erotismo, entre sexualidad y procreación por un lado, horror y muerte por el otro. "Para llegar a la cumbre del éxtasis, donde nos perdemos en el goce”. Pero es necesario poner siempre el límite al horror" que se esconde bajo el signo de sexo y angustia. Son esas perversas dualidades que acompañan el erotismo: nacimiento y muerte (Goethe), pulsión de vida, pulsión de muerte (Freud) desde donde se construye el ser humano. El erotismo es una necesidad del ser humano para darle rumbo a su vida. Pero el erotismo es expresión de naturaleza sexual en sus dos vertientes: tan pronto empuja tanto al ser humano hacia la animalidad, el bestialismo, donde el erotismo se ve asimilado a la pornografía, el "satanismo" (Sade y Moreau); como también en el erotismo, dice Dadoun, la sexualidad participa de lo divino, es vía elegida hacia la armonía (Fourier), es el paraíso, la perfección en la tierra (El Bosco, los Hermanos y Hermanas del Libre Espíritu): el hombre fue creado por Dios, y el erotismo se alza hacia el maravilloso misterio de creación. Pero es necesario entender el erotismo en su relación dialéctica entre 
Eros y Tánatos, no en una dualidad excluyente: estamos en todo instante, con nosotras y nosotros mismos y con el otro(a), bajo esas dos pulsiones constitutivas del ser humano. $\mathrm{Y}$, es en ese sentido que entenderemos mejor la necesidad y búsqueda del placer y de la construcción del yo en sus implicaciones con el otro, con la sociedad, con el mundo y con la muerte: entre el ángel y la bestia.

Por ello, en la historia de Descifrar tu mirada, el conflicto erótico de lucha permanecía vivo especialmente en los disgustos entre Lisa y Marcos. El erotismo, entendido como lo estamos analizando impulsa a conquistar el mundo, a elaborar o a destruir sueños y utopías. En el erotismo, entonces, conviven Eros y Tánatos, es esa energía dialéctica y no dualista que nos hace sentir y saber que estamos en permanente proceso de estar siendo. No como seres acabados, terminados, sino en lucha cotidiana junto al otro y la otra. El erotismo nos desafía a hacernos y rehacernos permanentemente en nuestra relación con las otras y los otros, con el mundo.

Pero, ¿qué somos los seres humanos?, ¿de dónde venimos?, ¿a qué venimos?, ¿’por qué necesitamos del amor?, ¿’por qué no hay Eros sin Tánatos?, ¿cómo hacernos dueños de nuestro caminar?, ¿por qué no podemos avanzar sin la otra, el otro?

La conversión de los países en empresa, dentro de la lógica empresarial de ganancia, condujo al diseño de realidades económicas virtuales que nada tienen que ver con la realidad real de miseria, desempleo, pobreza y hambre en la mayor parte de los pueblos del mundo.

En síntesis, el libro Descifrar tu mirada permitió a las y los estudiantes entrar de otra forma en el análisis de los conceptos mencionados donde el primer libro escrito en torno a la "pedagogía erótica", Eros en el aula. Diálogos con Ymar ${ }^{36}$ debería hacer camino en el aula, como manifestación de vida, de creatividad, de generosidad, de erotismo, de amor y que se expresa de múltiples formas en cada ser humano y en la sociedad. Ese erotismo, antepuesto al de Tánatos tiene su acento, entre otras cosas, en las relaciones sociales marcadas por esas partes muy primitivas del ser humano y que son filicidas, parricidas, fratricidas, suicidas e incestuosas. El concepto de erotismo, en la historia de Lisa y Marcos, al juntar razón y emoción permite conocer, entre otras cosas, esa sexualidad del cuerpo como expresión e impulso de la libido convertida en deseo. Y es, el erotismo de Eros que lleva a Marcos a no bajar los brazos por el amor de Lisa, 
por el sentido de la vida que con ella se convertía en flor, aroma e impulso de vivir juntos, amándose y reinventando una sociedad donde sea menos difícil amar, donde se respete al otro/a y que, al "mandar obedeciendo", diga y haga siempre no a la eliminación del hermano y la hermana: "principio ético zapatista, no negociable y esencia de la dignidad humana".

Sin embargo, el camino de Eros no es fácil, es importante entender que la mayor parte de estudiantes que han participado en este proceso si bien es cierto que se comprometen en la lectura de su práctica, no llegan a entender la importancia de juntar teoría y práctica, de hacer suya una praxis transformadora a favor de otra sociedad donde no exista la explotación capitalista y donde se mande obedeciendo. Una propuesta hermosa de cómo entender el erotismo de Eros como lucha nos propone el Subcomandante Marcos, jugando entre el amor de pareja y el amor de una sociedad que evoca y convoca a la lucha por construir un mundo donde quepan muchos mundos: ${ }^{37}$

$\mathrm{Ni}$ un gesto como respuesta.

Sombra imagina dudas que, en el corazón de ella, toca a él disipar.

Un mar de viento y lluvia ha iluminado la noche que camino. Firme en el timón, espero el faro de vuestras letras para salvarme y salvaros.

Vamos marinera mía. Venga a andar el deseo con el capitán tomándole la mano. Venga, vamos, deje usted pendientes las angustias y las penas que se le hacen mar en la mirada. Venga con el capitán, marinera clara. Venga y volvamos al nosotros.

Volvamos al ansia que, de día toma mi mano y de noche mi paso, para escribiros

[...]

Este tiempo no me permite nada, marina esperanza, ni un suspiro siquiera, bailo bailando la danza de la vida en el filo de la 
muerte, corre a la inversa el reloj de la vida, acechan la traición $y$ la desventura.

No hay mañana, noche marinera, tengo el rostro, el nombre y el pasado amordazados, el futuro me fue negado, vivo el presente como viven los auténticos guerreros: en un suspiro y de prestado. Todo pido, agua marina, el alma entera.

Sin su cuerpo junto al mío vuelven mis huesos y mis carnes a la única compañía que acepta sin condición: la tierra”.

Entonces, ¿en qué quedamos? ¿Viene usted?

Sea. Tome mi mano, cierre los ojos y sonría.

Lo verá usted: no hay placer más grande que caer hacia arriba... [grifo do autor]

Como termómetro social el aula es, casi siempre, un espacio psicótico, apartado de la realidad de las luchas sociales. Entendemos y compartimos la pluralidad democrática que debe existir en los espacios educativos que sin ser neutros tampoco son espacios para proselitismo político alguno.

Pero, la esperanza se construye en la lucha y no en la espera y, como dicen y hacen las y los zapatistas no somos pocos quienes creemos en ello, somos un "chingo". ${ }^{8}$

Compañeros y compañeras, abuelos y abuelas, niños y niñas, hombres y mujeres de aquí y de allá; así comenzaba Don Juan su palabra, sin olvidar a nadie, acobijando con su voz pausada y firme las esperanzas de cada quien. Con su mirada profunda y honesta nos habría surco para que pisáramos firme en la tierra que se defiende, para que siga viva. Con su palabra verdadera y sabia, nos tocaba el corazón y la razón para no titubear en la lucha contra la destrucción, el pisoteo, el despojo y el olvido, "contra ese pulpo" - como él decía - que es el capitalismo. Con una inmensa rebeldía defendía y acompañaba la tierra, y hoy, Don Juan regresó a ella, plenamente, donde de por sí ya estaba con su corazón y convicción. 
Desde acá Don Juan, le damos las gracias por todo lo que nos enseńó, por todo lo que nos dijo, por las risas, por las palabras, por la música, por la dignidad de sus pasos que nos abren hoy camino para seguirle, para pelear por lo que nos queda y dar un espacio a nuestros sueños por un mundo que como usted, anhelamos diferente, mejor, donde todos y todas tengamos cabida con libertad y dignidad, donde nuestros derechos dejen de ser pisoteados, donde la soberbia no encuentre eco como tampoco la impunidad, donde la represión no tenga cobijo.

\section{La lectura de la realidad en el aula, la MRCyT}

En el salón de clases, entonces, ¿cómo estudiar la realidad educativa y social?, ¿cuál es su vinculación con la transmisión y construcción de conocimientos?, ¿por qué es necesario vincular el texto que se estudia con el contexto social?

Pensamos que esto no sólo es posible sino necesario. En nuestro proyecto, ante la complejidad de una lectura de la realidad en el aula, era indispensable delimitar nuestro estudio. Lo hicimos definiendo primero dos procesos educativos distintos, aunque nunca son exclusivos: la educación bancaria y la educación liberadora. Con estos referentes ubicamos las problemáticas a estudiar en el aula en tres vínculos educativos. Los que se establecen:

- Entre docente - estudiantes;

- Entre estudiantes y

- Entre docente - estudiantes con el conocimiento.

Se definió así, que en el aula propondríamos tanto la "pedagogía de la problematización" como la "pedagogía erótica" para subrayar la importancia de tener claridad en la definición de la problemática a estudiar, en su relación de lo cotidiano con la teoría. Pero también, que junto al problema que se estudia, el impulso de Eros puesto en un conocimiento como lucha por la vida en el aula es esencial. Y, esa relación dialéctica es la 
primera tarea educativa a la que hacemos énfasis cuando al comenzar cada asignatura, presentamos el proyecto de "La lectura de la realidad".

Para hacerlo, retomamos su memoria histórica. El proceso que permitió la elaboración de la Metodología para el rescate de la práctica y la Teoría, MRCyT, y el trabajo práctico y teórico realizado. Hacemos énfasis en que no es una metodología neutra sino que busca ser emancipadora, que cuestiona los procesos educativos donde no existen sujetos sino objetos. Ese depósito de conocimientos dogmáticos, fríos, abstractos, a-históricos y sin contexto social cultural: como si las y los estudiantes fuesen un objeto $\leftrightarrow$ mercancía sin pertenencia de clase social alguna; como si estuvieran exentos de las relaciones de opresión impuestas con el modelo de globalización neoliberal.

En síntesis, al iniciar cada asignatura se muestra como la MRCyT, al contrario de alentar esa transmisión bancaria, proponer un trabajo de creación de conocimientos. Tarea que no es posible si quienes participan no emergen como sujetos y, por ello, la importancia de su participación como sujetos desde el principio de la praxis. La MRCyT consta de dos ejes: el rescate de lo cotidiano y el rescate de la teoría.

\section{Rescate de lo cotidiano}

Actualmente la problemática que se está estudiando es la construcción del sentido de la vida (el sentido de la vida). Una vez definida la problemática el camino metodológico se centra en el análisis de la cotidianidad escolar, lo que denominamos con el nombre de rescate de lo cotidiano y lo hacemos a través de la organización deRepresentaciones Actuadas de una Problemática (RAPS). Pero, cabe señalar que también nos apoyamos en el análisis de películas que son de gran utilidad tanto para la observación y estudio de la racionalidad emocional: las imágenes y fantasías conscientes e inconscientes. Llamamos rescate a ese proceso para acentuar la necesidad de partir de la práctica estudiantil en el salón de clases. A cada grupo de estudiantes se les propone organizarse en equipos (dependiendo de la composición del grupo total de estudiantes) para realizar las RAPS que, en nuestra práctica de dos semestres, son elaboradas durante el primer semestre de la asignatura. 
En el trabajo por equipos, se redefine la problemática específica que se va a analizar, subrayando los vínculos educativos seńalados anteriormente. Ese proceso comienza con el diálogo en los equipos donde definen la representación que realizaran para ir luego al proceso de filmar y editar la RAP: ${ }^{39}$ pedimos que ya editados deben tener un tiempo máximo de 15 minutos para facilitar el trabajo de todo el grupo.

La dinámica que se sigue para la presentación y análisis de cada RAP es la siguiente: en primer lugar se ven todas las RAPS para obtener una percepción general de las mismas. Estas RAPS se suben a la página del proyecto para que se puedan observar y estudiar con más precisión. Posteriormente se analiza una por una, pidiéndole al equipo que la elaboró escuchar las opiniones y, posteriormente, dar a conocer lo que quisieron representar. Al terminar el análisis se pide que presenten un escrito que dé cuenta de todo el proceso.

La forma de trabajo en el análisis de las películas es la siguiente: una vez que se vieron las películas acordadas se elabora una reseña y se presenta al grupo, en power point, un resumen de sus principales imágenes y de los conceptos utilizados en el proyecto: los que son pertinentes para dicho análisis. Se insiste en la importancia de ir al cine para ver las películas, teniendo presente el juego que se establece entre imágenes, fantasías y palabras. Y este proceso de rescate de lo cotidiano termina con un texto que se escribe para dar cuenta de todo el proceso.

\section{Rescate de la teoría}

La dinámica seguida para el rescate de la teoría se enlaza con la presentación de trabajos señalados anteriormente. Esto posibilita la presentación y construcción de conceptos y categorías partiendo para ello, de los conceptos propuestos dentro del proyecto. Pero dichos conceptos son tan sólo una propuesta para la lectura de su práctica, donde lo que importa es dicha lectura y no los conceptos en sí mismos; aunque claro está que los conceptos son como puentes que conducen al otro lado y deben estar bien cimentados. Los conceptos son ventanitas que nos permiten tener múltiples lecturas y decidir lo que se quiere profundizar. Señalamos, entonces, la pertinencia de ellos y la forma como nos han permitido una mejor lectura 
y transformación de la práctica. Por ello, es necesario que los conozcan y analicen, para poder decidir o no su pertinencia.

Los conceptos elaborados los hemos tomado de Freire, del EZLN, del psicoanálisis sociopolítico y la pedagogía erótica y ellos, en la lectura de nuestra práctica permitieron la construcción de categoría. Estas son:

[...] la lectura de la realidad y pronunciamiento; percepción y mediación; sueños y utopías; el conocimiento como lucha; dialogicidad; mandar obedeciendo; la digna rabia; la dialéctica entre autoridad y libertad: la autoridad; la sombra introyectada del opresor; la dialéctica jefe, masa y sujeto; la dialéctica filicidio $\leftrightarrow$ fratricidio y eros vs. tánatos, crueldad y utopía.

Los resultados de este proceso se consolidaron con la organización, básicamente a cargo de estudiantes, de los Seminarios Freirianos Internacionales (hemos realizado seis) donde se comparten con estudiantes y profesores de otras universidades el proceso y los resultados vividos con la MRCyT, con sus logros y limitaciones. En el año escolar de agosto de 201 I a mayo de 20I2, la temática que guió la lectura de la realidad fue "La construcción del sentido de la vida" que a su vez se concretizó en el VI Seminario Freiriano Internacional con el nombre de "Construir otro mundo es posible si caminamos preguntando".

\section{Notas}

I Este texto fue presentado en la Universidad de Paris 8 - Centre d'études sur les médias, les technologies et l'internationalisation (CEMTI) - durante mi año sabático como investigador invitado de agosto de 2012 a agosto de 2013. El título es La lutte sociale est-elle possible dans la salle de cours? Paulo Freire, le mouvement zapatiste, la psychanalyse sociopolitique et la "Pédagogie Érotique".。

2 "Señaló José Cruz, comunero de Milpa Alta, en el mensaje leído en nombre del CNI. Después vinieron los saludos del pueblo yaqui de Sonora y kumiai de Baja California. Además, los mensajes hechos llegar de España, Francia y Estados Unidos." RAMÍREZ, Gloria Muñoz. Pueblos indios dan combativa y emotiva despedida a Don Juan Chávez. Disponible en: <http:// desinformemonos.org/2012/06/despedidadonjuan/>.

3 Desde las montańas del Sureste Mexicano. Por el Comité Clandestino Revolucionario Indígena -Comandancia General del EZLN. Subcomandante Insurgente Marcos. México, Diciembre del 20I2. Disponible en: (<http://enlacezapatista.ezln.org.mx/20I2/I2/2I/comunicado-delcomite-clandestino-revolucionario-indigena-comandancia-general-del-ejercito-zapatista-deliberacion-nacional-del-2I-de-diciembre-del-20I2/>). 
4 DADOUN, Roger. L'utopie haut lieu d'inconscient. Paris: Sens et Tonka, 200o. p. 39.

5 ESCOBAR, Miguel; VIEYRA, Merary; SILVA, Mayra;JIMENEZ, Cora. Descifrar tu mirada: De Caledonia a Careyes. 3. ed. cor. México: La Burbuja, Casa del Poeta Peruanozoro. p. 33.

6 Mi encuentro con la praxis de Paulo Freire comenzó en los años I970 tanto en la educación de adultos como en el salón de clases. Posteriormente en 1974 encontré a Freire en la Universidad de Ginebra, Suisa, y tuve la suerte de trabajar con él durante cuatro ańos durante mis estudios de doctorado. Y durante 6 meses me invitó a trabajar en São Tomé y Príncipe, en África. Esta vivencia freiriana me llevó a reinventarlo en el salón de clases.

7 La única página autorizada del EZLN y de las comunidades zapatistas donde se tiene cotidianamente información sobre su lucha de organización y resistencia es: (<http://enlacezapatista. ezln.org. $\mathrm{mx} />$ ).

8 Leer y escribir el mundo es pronunciar la palabra-mundo, la palabra-resistencia, la palabralucha, la palabra-revolución; es convertir la palabra en acción y la acción en palabra. En el pensamiento freiriano pronunciar es despertar la "cultura del silencio", es leer el mundo para transformarlo en un proceso dialéctico entre mundo y sujeto social, donde transformar es transformarse. En: ESCOBAR GUERRERO, Miguel. Pedagogía erótica: Paulo Freire y el EZLN. <http://www.lrealidad.filos.unam.mx/>.

9 “A tal grado es medular el vocablo "nosotros", que Lenkersdorf acuńó la palabra "nosotrificación” o relación "nosótrica". Resulta conveniente enfatizar que la comunidad no impide o reemplaza la decisión individual, como pudiera pensarse. El "tu" no se niega ni se aniquila sino que se transforma en la voz de todos los "tus" nacidos por el nosotros, con todas sus diferencias que acaban por complementarse. Lo que definitivamente no existe es la representación jerárquica de ningún jefe, líder u otra autoridad personal o de grupo. La comunidad nosótrica es una instancia colectiva que no sólo representa a la comunidad sino que la constituye, es la “comunidad”. ESCOBAR GUERRERO, Miguel. Pedagogía eróticaop. cit.

Io ESCOBAR GUERRERO, Miguel Poder y filicidio. Disponible en: <http://ru.ffyl.unam. $\mathrm{mx}: 8080 /$ jspui/handle/I039I/669>.

I I ESCOBAR GUERRERO, MiguelFernando Martínez Salazar y el psicoanálisis aplicado a lo social. Disponible en: <http://ru.ffyl.unam.mx:8080/jspui/handle/I0391/770>.

I2 FREIRE, Paulo. Pedagogía de la autonomía. México: Siglo XXI, I997.

I3 “El psicoanálisis sociopolítico” en ESCOBAR GUERRERO, Miguel. Pedagogía erótica. op. cit.

I4 Arnaldo Rascovsky, "Sobre el filicidio y su significación en la génesis acting-out y la conducta psicopática en Edipo”, en AYALA VILLARREAL, Jaime F.; MARTÍNEZ SALAZAR, Fernando et.al. Homenaje Postumo al Dr. Arnaldo Rascovsky. México: Asociación Psicoanalítica Mexicana, 1996 p. 32.

I5 Fernando Martínez S. "Freud, algunas contribuciones a lo social y a lo político”. Ponencia presentada en la Asociación Psicoanalítica Mexicana, A. C., en agosto de 1997. El Dr. Fernando Martínez Salazar es médico psiquiatra y psicoanalista. Es miembro tanto de la Asociación Psicoanalítica Mexicana, como de la Asociación Psicoanalítica Internacional. Desde hace dos ańos estoy trabajando con él en un grupo operativo que tiene como finalidad el estudio del psicoanálisis aplicado a lo social.

I6 "En la ética erótica todas las fuerzas psíquicas se organizan precisamente hacia el fin de Eros; la preservación y el crecimiento de la vida; en la hegemonía de Eros, Tanatos mismo, con su negación está puesto al servicio de la vida. Por el contrario, la moral tanática es aquella en la que "la moral" misma se pone al servicio de la muerte, en la que prevalecen las fuerzas destructivas $y$, en nombre de la virtud, del bien, de lo santo y lo divino, todo sentido moral es invalidado, comenzando con su invalidación en el propio interior del alma; ahí donde la crueldad del verdugo moral se asocia con las fuerzas más contrarias a la moralidad, e impide, de hecho, el desarrollo de todo lo vivo". G. GONZÁLEZ, Juliana. El malestar en la moral: Freud y la crisis de la ética. 2. ed. México: Facultad de Filosofía y Letras, Unam, I997. p. 264.

I7 MARTÍNEZ SALAZAR, Fernando. Sobre la educación (inédito). 
I8 El EZLN tomó la decisión de recorrer toda la República Mexicana con la finalidad de ir al otro, otra, escucharlo e invitarlo a decir su palabra desde una propuesta de abajo y a la izquierda para luchar en contra la explotación capitalista: su intención es compartir las tantas luchas multicolores que alumbran el camino hacia la construcción de un mundo que se reinvente de abajo hacia arriba, como lo proponía Paulo Freire. Al inicio de su recorrido el delegado Zero dijo: "Nosotros pensamos, los compańeros de la otra campaña, de la que somos parte los del EZLN, que nada nos van a dar. Nada que no conquistemos por nuestro propio esfuerzo, con nuestro esfuerzo organizativo para transformar las cosas”. BELLINGHAUSEN, Herman. Palenque son ruinas; los mayas aún vivimos: Marcos. La jornada, México, 4 enero 2006. p. I3.

I9 Los Acuerdos de San Andrés fueron firmados entre el Gobierno y el l'EZLN después de un proceso largo de negociaciones, pero esta firma no fue aceptada ni reconocida por Ernesto Zedillo, presidente de la República Mexicana. GILLY, Adolfo, "Memorias de una infamia Atenco no se olvida”, la Jornada, sábado, 9 Junio, 20I2. Disponible en: < (http://www.jornada.unam. $\mathrm{mx} / 2012 / 06 / 09 / o p i n i o n / o r z a r p o l)>$.

20 Ibidem

2 I MARCOS, Subcomandante. Voltán I. Un escarabajo en la Red (Durito versión freeware). Disponible en: <http://enlacezapatista.ezln.org. $\mathrm{mx} / 20 \mathrm{I}_{3} / \mathrm{o} / 2 \mathrm{2} /$ votan-i-un-escarabajo-en-lared-durito-version-freeware/>.

22 Son tres las materias impartidas. Dos en la licenciatura en el Colegio de Pedagogía: Problemas contemporáneos de la educación I y 2 y un Seminario de Filosofía I y 2. Otro, en la División de Estudios de Posgrado de la FFyL, en el Posgrado en Pedagogía: Seminario de Educación y Liberación.

23 En varias universidades de la República Mexicana. En el extranjero, por ejemplo, en el Institut Universitaire d'études du Développement, Iuéd - actualmente Institut de hautes études internationales et du développement (IHEID) - de l'Université de Genève, Suisse. Disponible en:http://ru.ffyl.unam.mx:8080/jspui/handle/I0391/675>.

24 La página del proyecto "La lectura de la realidad en el aula. Pensar la práctica para transformarla es...": Disponible en: <http://www.lrealidad.filos.unam.mx./>.

25 Aquí es de gran importancia señalar que en el mes de mayo de 2012 la protesta, rebelión y organización de estudiantes de universidades mexicanas, en el contexto de las elecciones presidenciales para ese año, se confrontaron con el candidato presidencial Peńa Nieto impuesto por la televisión, Televisa, y lo hicieron denunciando además la agresión que él ordeno contra el Pueblo de San Salvador Atenco. La protesta comenzó en una de las universidades más importantes de México donde sus estudiantes tienen un alto nivel económico. O sea, que la memoria histórica no se había perdido ni en los estudiantes ni en la sociedad.

26 Descifrar tu mirada... está acompañado de canciones. Disponible en: <http://www.lrealidad. filos.unam.mx/descifrar_tu_mirada_anexo $>$.

27 Naomi Klein. La doctrina del Shock: El auge del capitalismo del desastre. Barcelona: Paidós Ibérica, 2007. Pablo González Casanova. Disponible en: <http://es.scribd.com/doc/I500522I/ Ponencia-Don-Pablo-Gonzalez-Casanova> y MARCOS, Subcomandante. La cuarta guerra mundial. Disponible en: <http://www.inmotionmagazine.com/auto/cuarta.html>.

28 "Una pulsión de poder, podría decirse (das Machtbedürfnis) - lo que se traduce en inglés por 'craving for power', en francés por “besoin de puissance politique” (necesidad de poder político) -, caracteriza a la clase gobernante de toda nación [...] A pesar de la ingenuidad que Freud le atribuye en cuanto a las cosas de la psique, Einstein adelanta aquí una hipótesis que va en el mismo sentido de lo que será la respuesta de Freud, a saber, la pulsión de crueldad (es decir, en el fondo, una pulsión de muerte) va de la mano, sin reducirse a ello, de esta pulsión de poder [...] ¿Qué hacer con una irreductible pulsión de muerte y una invencible pulsión de poder [...]?”. DERRIDA, Jacques. Estados de ánimo del psicoanálisis: Lo imposible más allá de la soberana crueldad. Buenos Aires: Paidós, 200r. p. I4 y 33.

29 Esta forma de organizarse emergió cuando el candidato del PRI estuvo en una universidad privada, la Universidad Iberoamericana, la Ibero. Los y las estudiante le cuestionaron su vio- 
lencia contra el Pueblo de Atenco, además de ser un candidato construido por Televisa. Él y su equipo quiso hacer lo de siempre, despreciarlo y decirles que era acarreados por el candidato de la izquierda. Entonces, ellas y ellos decidieron subir un video a YouTube mostrando su rostro e identidad como estudiantes de la Ibero. Eran I3I y desde ahí apareció el \#Yo soy I32, o sea, todos los que se les unieron.

30 Sin embargo, en México nació también una excelente propuesta de un diario semanal que se consulta por internet. Disponible en: <http://desinformemonos.org/>.

3 I El Primer Festival Mundial de la Digna Rabia fue organizado por los zapatistas en el ańo de 2009. Disponible en: < http://enlacezapatista.ezln.org.mx/2010/or/24/primer-festival-mundialde-la-digna-rabia/>.

32 La Sexta, Sexta Declaración de la Selva Lacandona es esencial para entender hoy el movimiento zapatista. Disponible en: <http://enlacezapatista.ezln.org.mx/2005/II/I3/sexta-declaracion-dela-selva-lacandona/>.

33 DADOUN, Roger ESCOBAR GUERRERO, Miguel.Crueldad y utopia. Disponible en: $<$ http://ru.ffyl.unam.mx:8080/jspui/browse?type=author\&value $=$ Escobar+Guerrero\% ${ }_{2} \mathrm{C}+\mathrm{Mi}$ guel\&sort_by $=2$ \&order=DESC\&rpp=30\&etal=o\&submit_browse=Actualizar $>$.

34 El deseo, resorte esencial de todas las actividades humanas, es donde descansa la estructura humana de la sexualidad, equivalente a deseo sexual. Dadoun dice que: "Todo está en él": el deseo permanece siempre, "en alguna parte", insatisfecho. El deseo jala la utopía, es utopía en la construcción de la subjetividad. Su expresión es continua e intensa mientras que la pornografía, por ejemplo, es instantánea, veloz y fugaz. Georges Bataille funda su concepción del erotismo entre la prohibición y trasgresión. Para Wilhelm Reich la potencia orgásmica es la función biológica primaria y fundamental que posee el ser humano en común con todos los organismos vivos. El ser humano está también entre el ángel y la bestia, entre la pulsión de vida y la pulsión de muerte. DADOUN, Roger. L'erotisme. Paris: Presses Universitaires de France 2003.

35 DADOUN, Roger.El Erotismo. Madrid: Biblioteca Nueva, 2006. La versión original en francés, DADOUN, Roger. L'Érotisme. De l'obsecene au sublime. Paris: Quadrige, PUF, 2010.

36 ESCOBAR GUERRERO, Miguel. Eros en el aula: Diálogos con YMAR. Valencia: La Burbuja,2005.

37 MARCOS, Subcomandante Insurgente; RAMÍREZ, Antonio; HERRERA, Efraín. Noches de fuego y de desvelo. México: Colectivo Callejero, 2007. Canto IX.

38 A Don Juan Chávez Alonso. A la familia y amigos de Don Juan. A los que caminan abajo y a la izquierda donde el corazón palpita. Desde Francia: Don Juan Chávez, no lo olvidamos. París, 4 de junio del 20I2. Disponible en: <http://enlacezapatista.ezln.org.mx/20I2/o6/oz/francia-donjuan-chavez-no-lo-olvidamos/?utm_source=feedburner\&utm_medium=email\&utm_campai gn $=$ Feed $\% 3$ A+EnlaceZapatista+\%28Enlace+Zapatista\%29>.

\section{Referências básicas}

BELLINGHAUSEN, Herman. Palenque no son ruinas; los mayas aún vivimos: Marcos. La Jornada, México, 4 enero 2006.

DADOUN, Roger. L'erotisme. Paris: Presses Universitaires de France, 2003.

DERRIDA, Jacques. Estados de ánimo del psicoanálisis: Lo imposible más allá de la soberana crueldad. Buenos Aires: Paidós, 200I.

DESINFORMÉMOS: semanario en Internet. Disponible en: $<$ ( http:// desinformemonos.org/)>. 
ESCOBAR GUERRERO, Miguel. Eros en el aula: Diálogos con Ymar. Valencia: La Burbuja, 2005.

- Fernando Martinez Salazar y el psicoanálisis aplicado a lo social. Disponible en: <http://ru.ffyl.unam.mx:8080/jspui/handle/I0391/770>.

Pedagogía erótica: Paulo Freire y el EZLN. México: [s.n.], 20I2. Disponible en: <http://www.lrealidad.filos.unam.mx/>).

. Poder y filicidio. Disponible en: <http://ru.ffyl.unam.mx:8080/jspui/ handle/I039I/669>.

VIEYRA, Merary; SILVA, Mayra; JIMÉNEZ, Cora. Descifrar tu mirada: De Caledonia a Careyes. 3. ed. cor. México: La Burbuja, Casa del Poeta Peruano, 20 o.

FREIRE, Paulo. Pedagogía de la autonomía. México: Siglo XXI, I997.

GILLY, Adolfo. Memorias de una infamia Atenco no se olvida La Jornada, 9jun. 2012. Disponible en: <http://www.jornada.unam.mx/20I2/o6/og/opinion/orzarpol>

. Porqué Atenco no se olvida. Disponible en: <http://www.jornada.unam. $\mathrm{mx} / 2012 / 06 / 07 / o p i n i o n / o r 4 a I p o l>)$.

GONZÁLEZ G., Juliana. El malestar en la moral. México: Facultad de Filosofía y Letras, Unam, I997.

KLEIN, Naomi. La doctrina del Shock: El auge del capitalismo del desastre. Barcelona: Paidós Ibérica, 2007.

MARCOS, Subcomandante. La cuarta guerra mundial. Disponible en: <http:// www.inmotionmagazine.com/auto/cuarta.html> y <http://www.youtube.com/ watch?v=bA8uWDZdE4o $>$ ).

. El Viejo Antonio. 4. ed. cor. y aum. México: Eón2or2.

- "Comunicado" del Comité Clandestino Revolucionario Indigena-Comandancia General del EZLN. México, 2I dic. 20I2. Disponible en: http://enlacezapatista.ezln. org. $\mathrm{mx} / 20 \mathrm{I} 2 / \mathrm{I} 2 / 2 \mathrm{I} /$ comunicado-del-comite-clandestino-revolucionario-indigenacomandancia-general-del-ejercito-zapatista-de-liberacion-nacional-del-2I-dediciembre-del-2012/>.

RAMÍREZ, Antonio; HERRERA, Efraín. Noches de fuego y de desvelo. México: Colectivo Callejero, 2007. Canto IX.

MUÑOZ R., Gloria. Pueblos indios dan combativa y emotiva despedida a Don Juan Chávez. Disponible en: http://desinformemonos.org/20I2/o6/despedidadonjuan/). Pablo González Casanova, "Festival de la Digna Rabia”. Disponible en: <http:// es.scribd.com/doc/I500522I/>. 


\section{Referências gerais}

BATAILLE, Georges. El erotismo. México: Tusquets, I997.

BEILLEROT, Jacky. Ideologie du savoir/Militants politiques et enseignants. Bruselas: Casterman, I979.

BELLINGHAUSEN, Hermann. En Chiapas, guerra del desprecio. La Jornada, México, I6mar.1998. p. 6.

BOSCO, João. Educación liberadora: Dimensión metodológica. Bogotá: Asociación de Publicaciones Educativas, (s-f.). (El documento que tengo no tiene fecha)

DADOUN, Roger. El erotismo. Madrid: Biblioteca Nueva, 2003.

La psychanalyse politique. Paris: PUF, 1995.

. L'erotisme. Paris: PUF, 2003.

. L'utopie haut lieu d'inconscient. Paris: Sens \& Tonka, 2000.

DERRIDA, Jacques. Estados de ánimo del psicoanálisis: Lo imposible más allá de la soberana crueldad. Buenos Aires: Paidós, 2000.

ESCOBAR GUERRERO, Miguel;VARELA BARRAZA, Hilda. Introducción. En:

FREIRE, Paulo. La importancia de leer y el proceso de liberación. México: Siglo XXI, I984. . Admirar. En: STRECK, D. R.; REDIN, E.; ZITKOSKI, J. J. (Org.). 
Lo cotidiano en el salón de clases. Rompan Filas, México, año 4, n. I5, p. 2I-27, I992.

. Paulo Freire y la Educación Liberadora (antología). México: SEP-Ediciones El Caballito, Biblioteca Pedagógica, 1985.

- Paulo Freire y la Pedagogía de la Pregunta. En: RUEDA, Mario et al. El aula universitaria: Aproximaciones metodológicas. México: Cise-Unam, 1991. p. 345-359.

- Pensar la práctica para transformarla: Freire y la educación de educadores de adultos. Xátiva, EspañaL’Ullal Edicions, 200I. (Diálogos).

. Percepción y lectura de la realidad. Diálogos, Barcelona, año IX, v. 34-35, n. 2, p. $\mathrm{I} 2 \mathrm{I}-\mathrm{I} 38,2003$.

_-_-_-_. Sonhos e utopias: Leer a Freire a partir de práctica. Brasília, DF: Liber Livro, 2010.

ESCOBAR GUERRERO, Miguel, FERNÁNDEZ, Alfredo;GUEVARA, Gilberto. Paulo Freire on Higher Education: A dialogue at the National University of Mexico. Nueva York: State University of New York, 1994.

FREIRE, Paulo. Acção cultural para a libertação e outros escritos. Lisboa: Moraes, I977. . Cartas a Cristina: Reflexiones sobre mi vida y mi trabajo. México: Siglo XXI, 1996

. Cartas a Guinea-Bissau. 8. ed. México: Siglo XXIı987.

. Cartas a quien pretende enseñar. México: Siglo XXI, I994.

. Cultura y liberación. En: ESCOBAR, M. (Conferencia de Paulo Freire en São Tomé el I2 de diciembre de i976).

Diccionario. 2. ed. rev. e ampl. Coordinador del Proyecto Danilo R.Streck. Belo Horizonte: Auténtica, 2010.

. Educação: O sonho possível. In: BRANDÃO, Carlos Rodrigues (Org.). $O$ Educador: Vida e Morte. 7. ed. Rio de Janeiro: Graal, I986. p. 89-IoI.

. Educación y actualidad brasileña. México: Siglo XXI, $200 \mathrm{I}$.

- ¿Extensión o comunicación? La concientización en el medio rural. 2. ed.

México: Siglo XXI, I975.

- La importancia de leer y el proceso de liberación. 6. ed. Introducción de Miguel Escobar G. e Hilda Varela Barraza. México: Siglo XXIı988

Pedagogía de la autonomía. México: Siglo XXI, 1997. 
. Pedagogía de la esperanza: Un reencuentro con la pedagogía del oprimido.

México: Siglo XXI, I994.

. Pedagogía de la indignación. Madrid: Morata. 2001.

. Pedagogía del oprimido. México: Siglo XXI, I970.

Politica y educación. México: Siglo XXI, 1996.

- Cuatro Cartas a los Animadores de los Círculos de Cultura de Soo Tomé e

Príncipe, México, La Mano, 2007.

. Una bibliografía. Moacir Gadotti y Carlos Torres. México: Siglo XXI, $200 \mathrm{.}$

; BETTO, Frei. Essa escola chamada vida. 4. ed. Sao Paulo: Ática, I986.

; FAUNDEZ, Antonio. Hacia una Pedagogía de la pregunta. Buenos Aires: La Aurora, I986.

; GADOTTI, Moacir; GUIMARAES, S. Pedagogía: diálogo e conflito. 2. ed. Sáo Paulo: Cortez/Autores Associados, 1986.

; ILLICH, Iván. Diálogo. Buenos Aires: Búsqueda, I975.

; MACEDO, Donaldo. Alfabetización: Lectura de la palabra y lectura de la realidad. Barcelona: Paidós, I989

FREUD, Sigmund. El malestar en la cultura. In: BRAUNSTEIN, Nestor A. (Coord.) A medio siglo de El malestar en la cultura de Sigmund Freud. México: Siglo XXI, I98I. p. 96 a 102.

. El malestar en la cultura (I929-I930). In: BRAUNSTEIN, Nestor A.

(Coord.). A medio siglo de El malestar en la cultura de Sigmund Freud. México: Siglo XXI, I985. p. I24-I 29.

GONZÁLEZ CASANOVA, Pablo. El saber y el conocer de los pueblos. Trabajo presentado en Primer Coloquio Internacional In Memoriam Andrés Aubry. San Cristobal de las Casas, Chiapas: Cideci Uniterra, 2009. p. 293-316

GONZÁLEZ, Juliana. El malestar en la moral: Freud y la crisis de la ética. 2. ed. México: Facultad de Filosofía y Letras, Unam y Grupo Editorial Miguel Ángel Porrúa, 1997.

LENKERSDORF, Carlos. Aprender a escuchar: Enseñanzas maya-tojolabales. México: Plaza y Valdés, 2008.

MARCOS, Subcomandante Insurgente. A la Marcha europea contra el desempleo, la precariedad y las exclusiones. Europa Rebelde. Planeta Tierra. La Jornada, México, I 4 jun. I997. p. II. 
. Corte de caja. Entrevista al subcomandante Marcos. Entrevista de Laura Castellanos. México: Bunker, 2008.

. Cuentos para una soledad desvelada. México: Ediciones del Frente Zapatista de Liberación Nacional, 1997.

. Dignidad Rebelde. In: . CD Juntos por Chiapas. México, 1997.

. El Viejo Antonio. 3. ed. cor. y aum. México: Eón, 2012.

. En algún lugar de la Selva Lacandona. Aventuras y desventuras de Don Durito. México: Ediciones y Gráficos Eón, 2008.

. Ética y politica: mesa redonda. México: FFyL-Unam, Auditorio Che Guevara, Ciudad Universitaria de la Unam, 9 jun. 2007.

. México: entre el sueño, la pesadilla y el despertar. In: . La palabra de

los armados de verdad y fuego, 3. México: Fuenteovejuna, I995. p. I07-I08.

; RAMÍREZ, Antonio; HERRERA, Efraín. Noches de fuego y de desvelo. México: Colectivo Callejero, 2007. Canto IX.

MARTÍNEZ SALAZAR, Fernando. Arnaldo Rascovsky, Psicoanalista, Maestro y Amigo. En: AYALA VILLAREAL, Jaime F.; MARTÍNEZ SALAZAR, Fernando et al (Ed.). Homenaje Postumo al Dr. Arnaldo Rascovsky. México: Asociación Psicoanalítica Mexicana, 1996. p. 2 I.

. El amor y las relaciones de género. Trabajo presentado en el XLII Dialogo latinoamericano intergeneracional entre hombres y mujeres, Ciudad de Guanajuato, 3I oct. y I-2 nov. 2002. lrealidad.unam.mx>.

. El amor y las relaciones de género. México, 2002. Disponible en: www.

. El subcomandante Marcos y la percepción de la realidad. Trabajo presentado en la XXIII Reunión Anual Sigmund Freud, de la Asociación Psicoanalítica Mexicana, A.C. celebrada los días 3, 4 y 5 mayo 200I, en el Hotel Hacienda de Vistahermosa de Tequesquitengo, Morelos, México. Disponible en: <www.lrealidad.unam.mx>).

. Freud, algunas de sus contribuciones a lo cultural y lo político.Rompan Filas: México, n. 43, p. 26-331999.

- Psicoanálisis, amor y poesía. Trabajo presentado en el XLIV Congreso Nacional de Psicoanálisis, con el tema Amor y Trauma. Una visión psicoanalítica, Ciudad de Oxaca, de 25 al 27 nov. 2004. Disponible en: <www.lrealidad.unam.mx>).

. Realidad, psicosis y farmacodependencia. Trabajo presentado en la reunión científica anual Sigmund Freud, en el Hotel Ixtapan: Ixtapan de la Sal, Estado de México, el I8 mayo I996. Disponible en: <www.lrealidad.unam.mx>). 
MUÑOZ R., Gloria. 20 y 10 el fuego y la palabra. México: Edición Revista Rebeldía, 2003.

NAVARRO, Fernanda. [La Autora presento su ponencia al lado del Subcomandante Marcos quien habló de "Dos éticas y una política, o de cómo no hay que buscar donde se está mejor, sino donde está el deber. La ética del Guerrero México, 2007. Disponible en: <http://www.lrealidad.filos.unam.mx/etica-y-politica>. XXI2005.

Louis Althusser: Filosofía y marxismo. Entrevista. 3. ed. México: Siglo

. Presentación del libro Descifrar tu Mirada. México: FFyL-Unam, 29 oct. 2010.

RASCOVSKY, Arnaldo. El filicidio y su trascendencia en la motivación inconsciente de guerra en Freud y otros: El psicoanálisis frente a la guerra. Buenos Aires: Rodolfo Alonso Editor, I970

REBELLATO, José Luis. Globalización educativo y cultural: integración o construcción de alternativas? Diálogos: Barcelona, n. 19-20, p. 7-28, I999.

VILLORO, Luis. Crecer, saber, conocer. I4. reimpr. México: Siglo XXI2009.

. (Coord.). Los linderos de la ética. 3. ed. México, Siglo XXI, 2005.

. Otra visión del mundo es posible”, La jornada I8 de enero de 2009.

Disponible en: <http://www.jornada.unam.mx/2009/oI/I8/index.php?section=opinion \&article $=$ or 8 a ipol.

Recebido em II nov. 2013 / Aprovado em I2 dez. 2013

\section{Para referenciar este texto}

ESCOBAR GUERRERO, M. La reinvención freiriana en la universidad: Paulo Freire, el movimiento zapatista, el psicoanálisis sociopolítico y la pedagogía erótica. EccoS, São Paulo, n. 32, p. 237-268. set/dez. 2013. 